\title{
Molecular characterization, polymorphism of the ACOX1 gene and association with ultrasound traits in Bos taurus
}

\author{
Y. Jiao ${ }^{1}$, L.S. Zan ${ }^{1,2}$, Y.F. Liu ${ }^{1}$ and H.B. Wang ${ }^{1,2}$ \\ ${ }^{1}$ College of Animal Science and Technology, Northwest A\&F University, \\ Yangling, Shaanxi, P.R. China \\ ${ }^{2}$ National Beef Cattle Improvement Center, Northwest A\&F University, \\ Yangling, Shaanxi, P.R. China \\ Corresponding author: L.S. Zan \\ E-mail: zanls@yahoo.com.cn
}

Genet. Mol. Res. 10 (3): 1948-1957 (2011)

Received August 24, 2010

Accepted February 28, 2011

Published September 9, 2011

DOI http://dx.doi.org/10.4238/vol10-3gmr1036

\begin{abstract}
Acyl-coenzyme A oxidase 1 (ACOX1) is the first enzyme in peroxisomal fatty acid $\beta$-oxidation; it is rate-limiting and plays a key role in fatty acid metabolism and fat deposition. ACOX1 is an important candidate gene for meat quality selection through marker-assisted selection. Genomic structural analysis showed that bovine ACOX1 shares $86 \%$ identity with human ACOX1. Using PCR-SSCP technology, we discovered a single nucleotide polymorphism (SNP) (A1865C) in exon 13 of the ACOX1 gene. Allele frequencies of this SNP were investigated and evaluated with the $\chi^{2}$ test in 641 cattle populations; only the Jiaxian red population was not in Hardy-Weinberg equilibrium. Gene heterozygosity, effective allele numbers and polymorphism information content of the bovine ACOX1 locus in seven populations varied from 0.2778 to 0.4954 , 1.3846 to 1.9817 and 0.2392 to 0.3727 , respectively. We also looked for a potential association of this SNP with ultrasound traits in 327 individuals and found a significant effect on ultrasound backfat thickness and ultrasound marbling score $(\mathrm{P}<0.05)$. Meat quality traits were analyzed in another 71 Qinchuan individuals to determine associations with genotype.
\end{abstract}


Animals with genotype AA had higher mean values of backfat thickness than those with genotypes $\mathrm{AC}$ and $\mathrm{CC}$. A represents the base before mutation and $\mathrm{C}$ represents the base after mutation. We conclude that this SNP of the ACOX1 gene has potential as a genetic marker for meat quality traits in cattle reproduction and breeding.

Key words: Cattle; ACOX1 gene; SNP; PCR-SSCP; Ultrasound traits

\section{INTRODUCTION}

Peroxisomal $\beta$-oxidation of fatty acids is catalyzed by enzymes that are immunologically distinct from the analogous mitochondrial enzymes. Acyl-coenzyme A oxidase 1 (ACOX1) catalyzes the first, rate-limiting step in peroxisomal $\beta$-oxidation of medium to very long straight-chain fatty acids (Fournier et al., 1994; Li et al., 2000; Morais et al., 2007). It catalyzes the desaturation of acyl CoAs to 2-trans-enoyl-CoAs, thereby producing $\mathrm{H}_{2} \mathrm{O}_{2}$ (Varanasi et al., 1994).

ACOX1 is a highly conserved enzyme with a distinct pattern of expression, which indicates an important role in lipid metabolism (Nohammer et al., 2000; Morais et al., 2007). Sequence analysis of the ACOX1 gene revealed high amino acid homology with rat (96\%) and human (87\%), and minor homology with other related proteins as well (Nohammer et al., 2000). mRNA and protein expression of ACOX1 is most abundant in liver followed by kidney, brain and adipose tissue, which illustrates its role in fat deposition (Nohammer et al., 2000; Zuo et al., 2007a). It is reported that ACOX1 alternative splicing isoforms also play a conserved key role in vertebrate fatty acid metabolism (Morais et al., 2007). Besides, several studies have found that the porcine ACOX1 gene is most closely linked to significant quantitative trait loci (QTL) affecting average daily gain, birth weight, backfat thickness, and fatty acid composition (Casas-Carrillo et al., 1997; Clop et al., 2003; Yue et al., 2003). ACOX1 gene expression was significantly increased in mice fed a high-fat diet, compared with a low-fat diet (Kim et al., 2004), and homozygous ACOX1-null mice were viable, but growth-retarded and infertile (Fan et al., 1996). In humans, the absence or mutation of the ACOX1 gene has been reported to be associated with the human disease of peroxisomal $\beta$-oxidation deficiency in several studies (Wanders, 2004; Rosewich et al., 2006; Oaxaca-Castillo et al., 2007). Thus, the ACOX1 gene is a potential positional candidate gene for traits related to fat deposition, given its role in the metabolism of fatty acids.

To our knowledge, there is no reported information so far on the polymorphism of the bovine ACOX1 gene. Based on the important roles of ACOX1 in fatty acid metabolism and fat deposition, ACOX1 could be an attractive candidate gene for meat quality traits in cattle. Therefore, the objective of this study was to detect single nucleotide polymorphisms (SNPs) of the bovine ACOX1 gene and to explore their possible association with meat quality traits in Bos taurus.

\section{MATERIAL AND METHODS}

\section{DNA samples and data collection}

A total of 712 adult animals were randomly selected from breeding populations and used to analyze ACOX1 allelic frequencies, including Qinchuan (QC, N =368, Shaanxi Prov- 
ince), Nan yang ( $N Y, N=48$, Henan Province), Jiaxian red (JR, $N=70$, Henan Province), Xia'nan (XN, N =63, Henan Province), Luxi (LX, N = 58, Shandong Province), Simmental and Luxi crossbred steers (SL, N = 52, Shandong Province), Xuelong (XL, N = 53, Liaoning Province). A total of 327 animals were selected to collect ultrasound measurements (Brethour, 1994; Hamlin et al., 1995), including ultrasound backfat thickness (UBF), ultrasound lean muscle area (ULMA) and ultrasound marbling score (UMAR). Apart from that, 71 QC steers, 1.5 to 2 years old, were randomly selected and slaughtered to determine meat quality traits, including backfat thickness (BFT), loin-eye area (LEA), marbling score (MAR), water-holding capacity (WHC), and tenderness (TD). In order to minimize systematic error, a single person was assigned to measure one of the three traits in all animals.

Genomic DNA samples were obtained from the 712 animals. DNA samples were extracted from leukocytes and tissue samples using a standard phenol-chloroform protocol (Mullenbach et al., 1989).

\section{Sequence analysis}

The ACOX1 gene amino acid sequences of different species were acquired from the National Center for Biotechnology Information (NCBI) server (http://www.ncbi.nlm.nih.gov), including Bos taurus (GenBank Accession No. DAA18210.1), Homo sapiens (GenBank Accession No. NP_004026.2), Mus musculus (GenBank Accession No. NP_056544.2), Rattus norvegicus (GenBank Accession No. NP_059036.1), Sus scrofa (GenBank Accession No. NP_001094498), and Gallus gallus (GenBank Accession No. NP_001006205). The bovine ACOX1 gene was compared with the corresponding protein of other species. The translated polypeptide sequences were aligned using the ClustalX software with the default parameters. Phylogenetic trees were constructed using the MEGA program (http://www.megasoftware.net/).

\section{Polymerase chain reaction (PCR) amplification}

According to the sequence of the bovine ACOX1 gene (GenBank accession No. NC_007317), one pair of primers (5'-GCTCGTTTCTTCGCTTTAGGGGA-3' and 5'-AAGCAGGAAGGCCCTCAGAGAA-3') was designed to amplify a 303-bp product of the ACOX1 exon 13 and its intron region. PCR amplifications were performed in a $20-\mu \mathrm{L}$ reaction mixture containing $50 \mathrm{ng}$ DNA, $10 \mathrm{pM}$ of each primer, $0.20 \mathrm{mM}$ dNTP, $2.5 \mathrm{mM}$ $\mathrm{MgCl}_{2}$ and $0.5 \mathrm{U}$ Taq DNA polymerase (TaKaRa, Dalian, China). The cycling protocol was $5 \mathrm{~min}$ at $95^{\circ} \mathrm{C}$ and 31 cycles of denaturing at $94^{\circ} \mathrm{C}$ for $30 \mathrm{~s}$, annealing at $63.7^{\circ} \mathrm{C}$ for $30 \mathrm{~s}$ and extension at $72^{\circ} \mathrm{C}$ for $30 \mathrm{~s}$, followed by a final extension for $10 \mathrm{~min}$.

\section{Single-stranded conformation polymorphism (SSCP) and sequencing}

Aliquots of $7.5 \mu \mathrm{L}$ of the PCR product were mixed with $11 \mu \mathrm{L}$ denaturing solution ( $95 \%$ formamide, $25 \mathrm{mM}$ EDTA, $0.025 \%$ xylene-cyanole and $0.025 \%$ bromophenol blue), heated for $10 \mathrm{~min}$ at $98^{\circ} \mathrm{C}$ and chilled on ice. Denatured DNA was subjected to polyacrylamide gel electrophoresis (PAGE) $(80 \times 73 \times 0.75 \mathrm{~mm})$ in $1 \mathrm{X}$ Tris-borate EDTA (TBE) buffer at constant voltage $(120 \mathrm{~V})$ for $18-20 \mathrm{~h}$. The gel was stained with $0.1 \%$ silver nitrate (Lan et al., 2007). After the polymorphism was detected, the PCR products of different electrophoresis 
patterns were purified with Axygen kits (MBI Fermentas, Canada) and sequenced in both directions in an ABI PRIZM 377 DNA sequencer (Perkin-Elmer, USA). The sequences were analyzed with the SeqMan software.

\section{Statistical analysis}

Based on the genotype number of the ACOX1 exon 13 and its flanking region locus in Bos taurus breeds analyzed, the following items were statistically analyzed according to previous approaches (Liu et al., 2010; Jiao et al., 2010), including genotypic frequencies, allelic frequencies, Hardy-Weinberg equilibrium, gene homozygosity, effective allele numbers, and polymorphism information content (PIC). The association between SNP marker genotypes of the ACOX1 gene and records of ultrasound traits (UBF, ULMA and UMAR) was analyzed by the least-squares method as applied in the GLM procedure of SAS (SAS Institute Inc., Cary, $\mathrm{NC}$, USA) according to the following statistical linear model:

$$
\mathrm{Y}_{\mathrm{ijkl}}=\mu+\mathrm{G}_{\mathrm{i}}+\mathrm{S}_{\mathrm{j}}+\mathrm{BF}_{\mathrm{k}}+\mathrm{Ma}_{1}+\varepsilon_{\mathrm{ijkl}} \quad \text { (Equation 1) }
$$

Meat quality traits (BFT, LEA, MAR, WHC, and TD) were also evaluated by comparing the genotypes of 71 Qinchuan individuals with respect to their phenotypic data by the least-squares method according to the following statistical linear model:

$$
\mathrm{Y}_{\mathrm{ijkl}}=\mu+\mathrm{G}_{\mathrm{i}}+\mathrm{S}_{\mathrm{j}}+\mathrm{Ma}_{1}+\varepsilon_{\mathrm{ijk} 1}
$$

where $Y_{i j k l}$ is the observation for ultrasound measurements, $\mu$ is the overall mean for each trait, $G_{i}$ is the genotype effect, $S_{i}$ is the fixed effect of sex, $B F_{k}$ is the fixed effects of breed and farm, $M a_{l}$ is the regression variable for measured age, and $\varepsilon_{i j k l}$ is the random environment effect.

\section{RESULTS}

\section{Sequence alignments and inferred phylogenetic tree}

A GenBank database search using BLAST revealed that the bovine ACOX1 amino acid sequence shared high similarity with ACOX1 protein sequences of other species, showing $86 \%$ identity with human and $83 \%$ identity with mouse. Hitherto, the phylogenetic relationship among all characterized members of the ACOX1 gene was illustrated according to the phylogenetic distance calculated by the MEGA 4.0.1 program (Figure 1). Phylogenetic tree analysis was employed to find the positions of bovine ACOX1 in relation to a selection of other animals; ACOX1 of bovine and human, fell into one evolutionarily related group, excluding mouse, rat, chicken, and pig. Like their orthologous genes in human, mouse, rat, chicken, and pig, the bovine ACOX1 gene shows the highest homologies in its middle part, whereas the amino and carboxyl termini are less conserved. These conserved amino acid residues are indicated with asterisks in Figure 2.

\section{Genetic variation}

After 303-bp products of the bovine ACOX1 gene were amplified, polymorphism of the ACOX1 gene in 712 cattle were detected by SSCP and confirmed by the DNA sequencing 


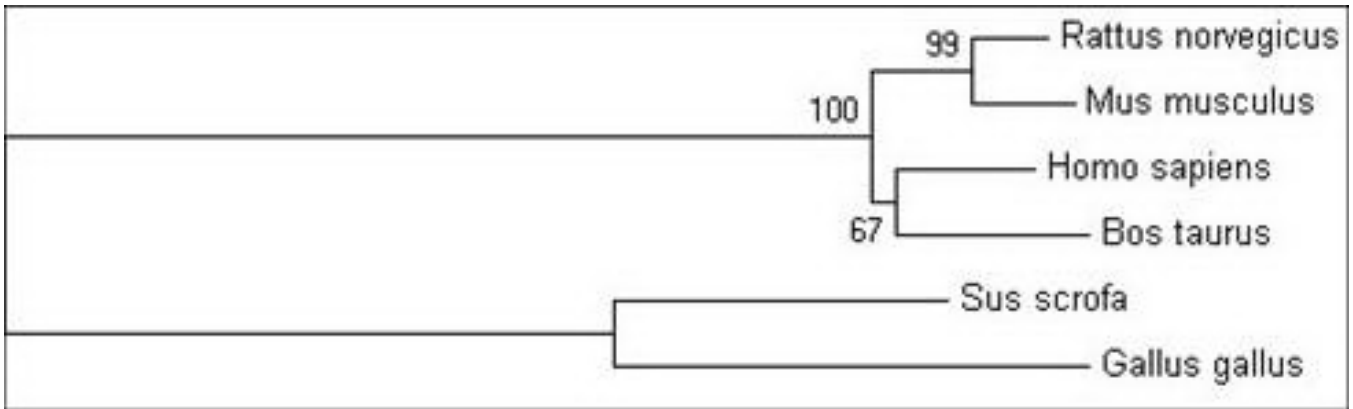

Figure 1. Phylogenetic tree of the ACOX1 gene in different species. The bootstrap confidence values are shown at the nodes of the tree. The horizontal branch lengths are proportional to the estimated divergence of the sequence from the branch point.

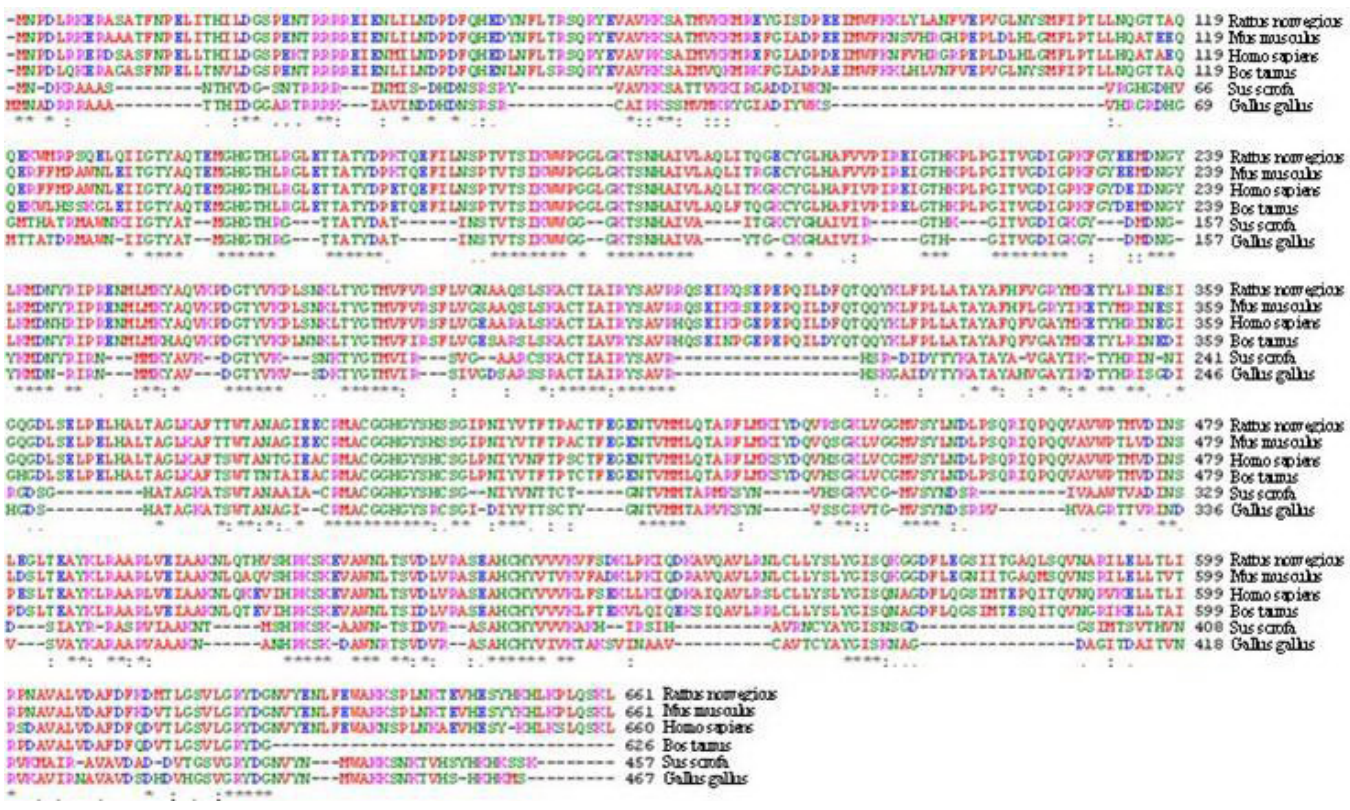

Figure 2. The deduced amino acid sequence of Bos taurus ACOX1 (GenBank Accession No. DAA18210.1) was aligned to that from Homo sapiens (GenBank Accession No. DAA18210.1), Mus musculus (GenBank Accession No. NP_056544.2), Rattus norvegicus (GenBank Accession No. NP_059036.1), Sus scrofa (GenBank Accession No. NP_001094498), Gallus gallus (GenBank Accession No. NP_001006205). Conserved amino acid residues among different species are shown with asterisks.

method. The result showed three unique SSCP patterns in the animals studied (Figure 3). In order to better understand the detailed genetic variations within the Chinese cattle ACOX1 gene, the three polymorphic SSCP patterns of exon 13 and its flanking region were sequenced and an $\mathrm{A} / \mathrm{C}$ mutation was detected (Figure 4). Comparison between the nucleotide sequences of the bovine ACOX1 gene (GenBank Accession No. NC_007317) and the sequencing results revealed one novel SNP, designated $\mathrm{A} 1865 \mathrm{C}$. The $\mathrm{A}>\mathrm{C}$ mutation, a synonymous mutation 
of glycine, is located at position 1865 of the ACOX1 gene. With the sequence data from different individuals, three genotypes were described as: AA, AC and CC (Figure 3). The three genotypes corresponded to three polymorphic SSCP patterns found in this study, which were designated AA with two bands, $\mathrm{AC}$ with three bands and $\mathrm{CC}$ with two bands (Figure 3).

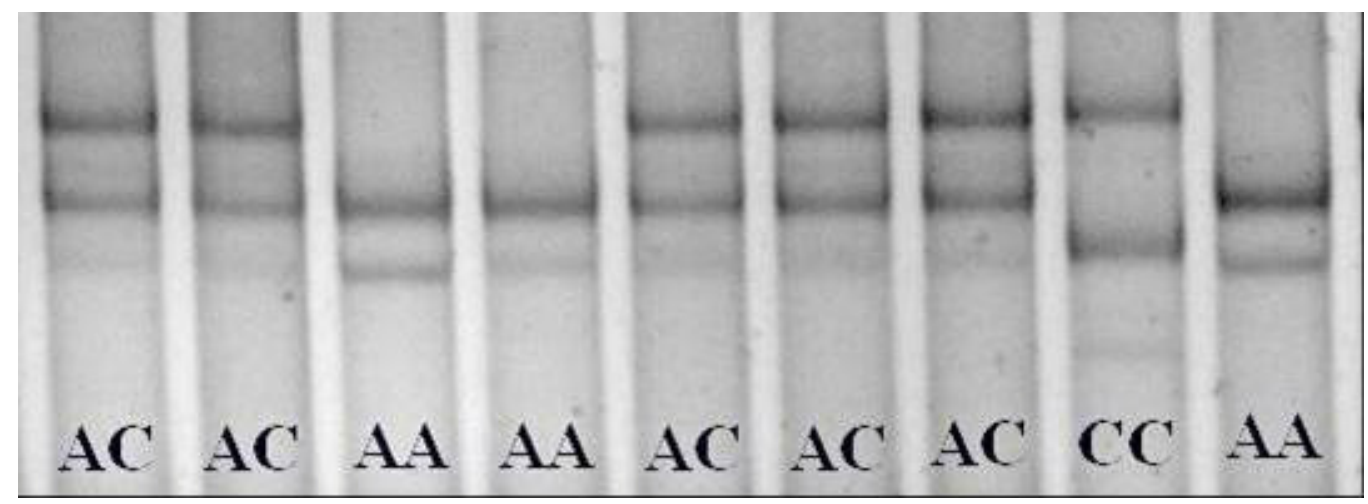

Figure 3. Polyacrylamide gel electrophoresis of PCR-SSCP.

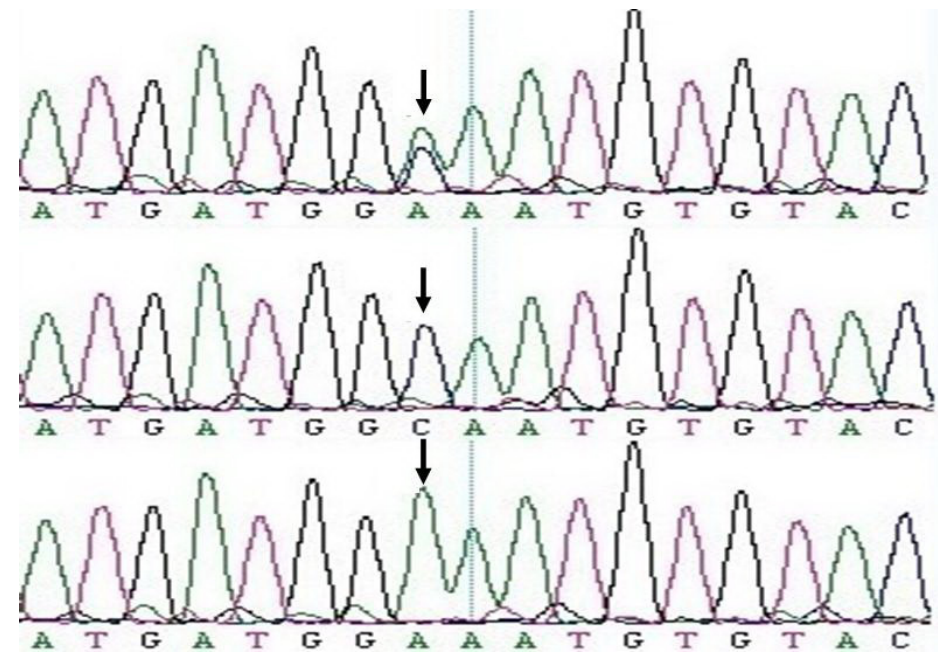

Figure 4. DNA sequence map of exon 13 and its flanking region at the bovine ACOX1 locus.

Moreover, allele frequencies of the SNP were investigated and evaluated by the $\chi^{2}$ test in all Bos taurus populations in our study (Table 1). The data shown here demonstrate that the range of frequencies of the ACOX1-A allele was from 0.4519 to 0.8333 among seven different subpopulations of the Bos taurus population. There was significant difference in the allelic frequency of the JR population $(\mathrm{P}<0.05)$, suggesting that JR was not in Hardy-Weinberg equilibrium. The frequencies of CC genotype were from 0.0317 in the $\mathrm{XN}$ population to 0.2885 in the SL population, which were relatively low in the seven populations. This observation is possibly because of the occurrence of random genetic drift due to the low frequency of allele 
C. In addition, we did not find the CC genotype in the NY population (shown in Table 1). There are a couple of possibilities for this observation: 1) the CC genotype possibly exists in the NY population, but there are not enough individuals in our study, or 2) the animals with the TT genotype do not exist in the NY population.

Table 1. Genotype frequencies (\%) at the ACOX1 gene for the SNP in bovine populations.

\begin{tabular}{|c|c|c|c|c|c|c|c|c|}
\hline \multirow[t]{2}{*}{ Breed } & \multicolumn{3}{|c|}{ Observed genotypes (number) } & \multirow[t]{2}{*}{ Total } & \multicolumn{2}{|c|}{ Allelic frequencies } & \multirow[t]{2}{*}{$\chi^{2}(\mathrm{HW})$} & \multirow[t]{2}{*}{$\mathrm{P}$ value $(\mathrm{HW})$} \\
\hline & $\mathrm{AA}$ & $\mathrm{AC}$ & $\mathrm{CC}$ & & A & $\mathrm{C}$ & & \\
\hline$\overline{\mathrm{QC}}$ & 0.3777 (139) & $0.4810(177)$ & $0.1413(52)$ & 368 & 0.6182 & 0.3818 & 0.13 & 0.9364 \\
\hline NY & $0.6667(32)$ & $0.3333(16)$ & $0.0000(0)$ & 48 & 0.8333 & 0.1667 & 1.92 & 0.3829 \\
\hline JR & $0.4429(31)$ & $0.3286(23)$ & $0.2286(16)$ & 70 & 0.6071 & 0.3929 & 6.78 & 0.0337 \\
\hline $\mathrm{XN}$ & $0.5556(35)$ & $0.4127(26)$ & $0.0317(2)$ & 63 & 0.7619 & 0.2381 & 1.19 & 0.5513 \\
\hline LX & $0.3966(23)$ & $0.4483(26)$ & $0.1552(9)$ & 58 & 0.6207 & 0.3793 & 0.13 & 0.9354 \\
\hline SL & $0.1923(10)$ & $0.5192(27)$ & $0.2885(15)$ & 52 & 0.4519 & 0.5481 & 0.12 & 0.9415 \\
\hline $\mathrm{XL}$ & $0.2642(14)$ & $0.6038(32)$ & $0.1321(7)$ & 53 & 0.5660 & 0.4340 & 2.78 & 0.2492 \\
\hline Total & $0.3989(284)$ & $0.4593(327)$ & $0.1419(101)$ & 712 & 0.6285 & 0.3715 & 0.19 & 0.9077 \\
\hline
\end{tabular}

$\mathrm{HW}=$ Hardy-Weinberg equilibrium; $\mathrm{QC}=$ Qinchuan; $\mathrm{NY}=$ Nan yang; $\mathrm{JR}=$ Jiaxian red; $\mathrm{XN}=$ Xia'nan; LX = Luxi; $\mathrm{SL}=$ Simmental and Luxi crossbred steers; $\mathrm{XL}=$ Xuelong.

Gene heterozygosity, effective allele numbers and PIC of the bovine ACOX1 locus in seven populations of the Bos taurus breed varied from 0.2778 to $0.4954,1.3846$ to 1.9817 and 0.2392 to 0.3727 , respectively (Table 2). Gene homozygosity was higher than gene heterozygosity in all Bos taurus breeds studied. Generally, PIC is classified into the following three types: low polymorphism (PIC value $<0.25)$, intermediate polymorphism $(0.25<$ PIC value $<0.5$ ) and high polymorphism (PIC value $>0.5$ ). According to this PIC classification, the NY population was classified at the low polymorphism level and the other populations belonged to the intermediate polymorphism level (Table 2).

\begin{tabular}{|c|c|c|c|c|}
\hline Breed & Gene homozygosity & Gene heterozygosity & Effective allele numbers & PIC \\
\hline $\mathrm{QC}$ & 0.5279 & 0.4721 & 1.8941 & 0.3606 \\
\hline NY & 0.7222 & 0.2778 & 1.3846 & 0.2392 \\
\hline $\mathrm{JR}$ & 0.5230 & 0.4770 & 1.9122 & 0.3633 \\
\hline $\mathrm{XN}$ & 0.6372 & 0.3628 & 1.5694 & 0.2970 \\
\hline LX & 0.5291 & 0.4709 & 1.8899 & 0.3600 \\
\hline $\mathrm{SL}$ & 0.5046 & 0.4954 & 1.9817 & 0.3727 \\
\hline $\mathrm{XL}$ & 0.5087 & 0.4913 & 1.9657 & 0.3706 \\
\hline Total & 0.5330 & 0.4670 & 1.8761 & 0.3579 \\
\hline
\end{tabular}

$\mathrm{PIC}=$ polymorphism information content. For breed abbreviations, see legend to Table 1.

\section{Association analysis}

We then analyzed three ultrasound traits (UBF, ULMA and UMAR) by comparing the genotypes of 327 individuals of the seven populations studied with regard to their phenotypic data. The results of association analysis are shown in Table 3. At the SNP marker, there are significant effects on UBF and UMAR $(\mathrm{P}<0.05)$, where animals with the AA genotype have higher mean values of UBF and UMAR than those with genotype AC or CC. Besides, we also analyzed the association between genotypes and meat quality traits, including BFT, LEA, MAR, WHC, and TD, in another 71 QC individuals. The results are shown in Table 4, 
from which we can see that there are significant differences between the different genotypes for BFT $(\mathrm{P}<0.05)$. Animals with the AA genotype have higher mean values for BFT than those with the $\mathrm{AC}$ and $\mathrm{CC}$ genotypes, but we did not find any association between genotypes and MAR phenotypic data. The $\mathrm{A}>\mathrm{C}$ synonymous mutation of glycine results in a decrease in part of the phenotypic variation, especially for the UBF phenotypes in the animals studied. Therefore, we assume that the mutation for A $1865 \mathrm{G}$ could have an important influence on many minor genes involved in backfat thickness and marbling score.

Table 3. Association between A1865C SNP genotypes of the ACOX1 gene and ultrasound traits in 327 Bos taurus.

\begin{tabular}{lccc}
\hline Genotype & & Traits $($ mean \pm SE) & UMAR \\
\cline { 2 - 4 } & UBF $(\mathrm{cm})$ & ULMA $\left(\mathrm{cm}^{2}\right)$ & $7.79 \pm 0.05^{\mathrm{a}}$ \\
\hline AA & $0.378 \pm 0.01^{\mathrm{a}}$ & $74.69 \pm 1.11$ & $7.71 \pm 0.04^{\mathrm{ab}}$ \\
AC & $0.357 \pm 0.01^{\mathrm{ab}}$ & $74.75 \pm 1.13$ & $7.55 \pm 0.11 \mathrm{~b}^{\mathrm{b}}$ \\
CC & $0.335 \pm 0.01^{\mathrm{b}}$ & $71.19 \pm 2.10$ & 0.0396 \\
$\mathrm{P}$ & 0.031 & 0.21 & \\
\hline
\end{tabular}

Means with different superscript letters are significantly different $(\mathrm{P}<0.05) . \mathrm{UBF}=$ ultrasound backfat thickness; $\mathrm{ULMA}=$ ultrasound loin-muscle area; UMAR $=$ ultrasound marbling score.

Table 4. Association between A1865C SNP genotypes of the MYPN gene and meat quality traits in 71 Qinchuan cattle.
\begin{tabular}{lccccc}
\hline Genotype & \multicolumn{5}{c}{ Traits (Means \pm SE) } \\
\cline { 2 - 6 } & BFT $(\mathrm{cm})$ & LEA $\left(\mathrm{cm}^{2}\right)$ & MAR & WHC & TD \\
\hline AA & $0.94 \pm 0.07^{\text {a }}$ & $81.33 \pm 0.10$ & $2.10 \pm 0.15$ & $0.24 \pm 0.01$ & $1.84 \pm 0.15$ \\
AC & $0.86 \pm 0.08^{\mathrm{b}}$ & $86.88 \pm 0.38$ & $2.24 \pm 0.10$ & $0.26 \pm 0.01$ & $2.02 \pm 0.11$ \\
CC & $0.85 \pm 0.31^{\mathrm{b}}$ & $79.44 \pm 1.22$ & $2.10 \pm 2.14$ & $0.27 \pm 0.05$ & $1.72 \pm 1.72$ \\
P & 0.0354 & 0.156 & 0.6910 & 0.0663 & 0.5886 \\
\hline
\end{tabular}

Means with different superscript letters are significantly different $(\mathrm{P}<0.05)$. BFT $=$ backfat thickness; LEA $=$ loineye area; $\mathrm{MAR}=$ marbling score; $\mathrm{WHC}=$ water-holding capacity; $\mathrm{TD}=$ tenderness.

\section{DISCUSSION}

The bovine ACOX1 amino acid sequence shared high similarity with ACOX1 protein sequences of other species, showing $86 \%$ identity with the human sequence and $83 \%$ identity with the mouse sequence. Bovine and human ACOX1 fell into one evolutionarily related group, excluding mouse, rat, chicken, and pig. Like their orthologous genes in the human, mouse, rat, chicken, and pig, the bovine ACOX1 gene shows the highest homologies in its middle part, whereas the amino and carboxyl termini are less conserved.

The meat quality traits of cattle are affected by many factors, such as genotype, sex, breed, herd, location, and other random environment factors. However, we established a new statistical model in which three factors (breed, herd and location) were involved, and we then employed the least-squares method in the GLM procedure of the SAS software to do the related analysis. However, we did not find any significant difference $(\mathrm{P}>0.05)$ (data not shown).

As we have pointed out, ACOX1 is the first and rate-limiting enzyme of fatty acid $\beta$-oxidation and plays an essential role in fatty acid degradation. Studies on polymorphism of the ACOX1 gene were conducted recently in both humans and pigs. Recently, a mutation in a splice site of the ACOX1 gene has been reported, which results in defective peroxisomal fatty acid $\beta$-oxidation (Oaxaca-Castillo et al., 2007). The absence of ACOX is associated with the 
human disease called pseudoneonatal-adrenoleukodystrophy (Wanders, 2004). While in the pig, Pst $\mathrm{I}$ variants in the ninth intron of the ACOX1 gene were examined for their influence on meat quality traits in 334 Large White $\times$ Meishan F2 pigs, and significant effects were found on fat deposition such as backfat thickness and carcass fat percentage of both longissimus dorsi and biceps femoris $(\mathrm{P}<0.05)$ (Zuo et al., 2007b). Above all, although many studies focus on ACOX1 gene variants, association studies in cattle and other livestock have never been reported. Therefore, based on these results of the genome-wide approach in porcine, considering the evolutionary conservation between cattle and pig, we applied the research results of porcine ACOX1 to analyze polymorphism and genetic effects on the cattle ACOX1 gene locus. The present study is the first to show that the A1865C SNP of bovine ACOX1 is significantly associated with ultrasound backfat thickness and ultrasound marbling score (Table 3) in cattle. These results are consistent with the findings reported in pigs.

In conclusion, we carried out a molecular characterization of the bovine ACOX1 gene, identified one SNP and investigated its association in seven Bos taurus populations. Our results provide evidence that the ACOX1 gene may have potential effects on meat quality traits in cattle. Therefore, further study will be necessary to use the SNP for marker-assisted selection in larger populations. It is also important to investigate whether the ACOX1 gene plays a role in the development of these traits and whether it involves in linkage disequilibrium with other causative mutations.

\section{ACKNOWLEDGMENTS}

Research supported by the China National 863 Program (\#2008AA1010 and \#2006AA10Z1A1), the National Eleventh "Five Year" Science and Technology Support Project (\#2006BAD01A10-3), and GMO new varieties major project (\#2008ZX08007-002). Moreover, the cattle populations were supported by the Qinchuan Beef Cattle Breeding Center of Shaanxi Province, Nanyang, Jiaxian and Xianan Cattle Breeding Center of Henan Province, Luxi Cattle Breeding Center of Shandong Province, and Snow Dragon Beef Cattle Breeding Center of Liaoning Province (P.R. China).

\section{REFERENCES}

Brethour JR (1994). Estimating marbling score in live cattle from ultrasound images using pattern recognition and neural network procedures. J. Anim. Sci. 72: 1425-1432.

Casas-Carrillo E, Prill-Adams A, Price SG, Clutter AC, et al. (1997). Mapping genomic regions associated with growth rate in pigs. J. Anim. Sci. 75: 2047-2053.

Clop A, Ovilo C, Perez-Enciso M, Cercos A, et al. (2003). Detection of QTL affecting fatty acid composition in the pig. Mamm. Genome 14: 650-656.

Fan CY, Pan J, Chu R, Lee D, et al. (1996). Hepatocellular and hepatic peroxisomal alterations in mice with a disrupted peroxisomal fatty acyl-coenzyme A oxidase gene. J. Biol. Chem. 271: 24698-24710.

Fournier B, Saudubray JM, Benichou B, Lyonnet S, et al. (1994). Large deletion of the peroxisomal acyl-CoA oxidase gene in pseudoneonatal adrenoleukodystrophy. J. Clin. Invest. 94: 526-531.

Hamlin KE, Green RD, Cundiff LV, Wheeler TL, et al. (1995). Real-time ultrasonic measurement of fat thickness and longissimus muscle area: II. Relationship between real-time ultrasound measures and carcass retail yield. J. Anim. Sci. 73: 1725-1734.

Jiao Y, Zan LS, Liu YF, Wang HB, et al. (2010). A novel polymorphism of the MYPN gene and its association with meat quality traits in Bos taurus. Genet. Mol. Res. 9: 1751-1758.

Kim S, Sohn I, Ahn JI, Lee KH, et al. (2004). Hepatic gene expression profiles in a long-term high-fat diet-induced obesity 
mouse model. Gene 340: 99-109.

Lan XY, Pan CY, Chen H, Zhang CL, et al. (2007). An Alul PCR-RFLP detecting a silent allele at the goat POU1F1 locus and its association with production traits. Small Ruminant Res. 73: 8-12.

Li Y, Tharappel JC, Cooper S, Glenn M, et al. (2000). Expression of the hydrogen peroxide-generating enzyme fatty acyl CoA oxidase activates NF-kappaB. DNA Cell Biol. 19: 113-120.

Liu YF, Zan LS, Li K, Zhao SP, et al. (2010). A novel polymorphism of GDF5 gene and its association with body measurement traits in Bos taurus and Bos indicus breeds. Mol. Biol. Rep. 37: 429-434.

Morais S, Knoll-Gellida A, Andre M, Barthe C, et al. (2007). Conserved expression of alternative splicing variants of peroxisomal acyl-CoA oxidase 1 in vertebrates and developmental and nutritional regulation in fish. Physiol. Genomics 28: 239-252.

Mullenbach R, Lagoda PJ and Welter C (1989). An efficient salt-chloroform extraction of DNA from blood and tissues. Trends Genet. 5: 391.

Nohammer C, El-Shabrawi Y, Schauer S, Hiden M, et al. (2000). cDNA cloning and analysis of tissue-specific expression of mouse peroxisomal straight-chain acyl-CoA oxidase. Eur. J. Biochem. 267: 1254-1260.

Oaxaca-Castillo D, Andreoletti P, Vluggens A, Yu S, et al. (2007). Biochemical characterization of two functional human liver acyl-CoA oxidase isoforms $1 \mathrm{a}$ and $1 \mathrm{~b}$ encoded by a single gene. Biochem. Biophys. Res. Commun. 360: 314-319.

Rosewich H, Waterham HR, Wanders RJ, Ferdinandusse S, et al. (2006). Pitfall in metabolic screening in a patient with fatal peroxisomal beta-oxidation defect. Neuropediatrics 37: 95-98.

Varanasi U, Chu R, Chu S, Espinosa R, et al. (1994). Isolation of the human peroxisomal acyl-CoA oxidase gene: organization, promoter analysis, and chromosomal localization. Proc. Natl. Acad. Sci. U. S. A. 91: 3107-3111.

Wanders RJ (2004). Peroxisomes, lipid metabolism, and peroxisomal disorders. Mol. Genet. Metab. 83: 16-27.

Yue G, Schröffel JJ, Moser G, Bartenschlager H, et al. (2003). Linkage and QTL mapping for Sus scrofa chromosome 12. J. Anim. Breed. Genet. 120: 95-102.

Zuo B, Yang H, Wang J, Lei MG, et al. (2007a). Molecular characterization, sequence variation and association with fat deposition traits of ACOX1 gene in pigs. J. Anim. Feed Sci. 16: 433-444.

Zuo B, Yang H, Lei MG, Li FE, et al. (2007b). Association of the polymorphism in GYS1 and ACOX1 genes with meat quality traits in pigs. Animal 1: 1243-1248. 